\title{
Characteristics of elastic waves passing through a flowable fill at early age
}

\author{
WooJin Han ${ }^{1}$, Yong-Hoon Byun ${ }^{2}$, and Jong-Sub Lee , $^{1, *}$ \\ ${ }^{1}$ Korea University, School of Civil, Environmental and Architectural Engineering, Seoul, South Korea \\ ${ }^{2}$ Kyungpook National University, School of Agricultural Civil \& Bio-Industrial Engineering, Daegu, South Korea
}

\begin{abstract}
Elastic waves obtained from transducers are widely used to monitor the strength and integrity of cementitious materials. A pair of bender elements (BEs) and piezo disk elements (PDEs) embedded in a cuboid mould are applied to monitor elastic waves passing through a cementitious material known as a flowable fill at early age. The flowable fills used in this study are mixed with calcium sulfoaluminate cement, sand, silt, fly ash, water, and an accelerator. Compressional and shear waves acquired from the PDEs and BEs, respectively, are observed for up to $72 \mathrm{hrs}$. Results show that the compressional and shear wave velocities increased with curing time. The sensors can be used effectively to monitor the hardening characteristics of flowable fills at early age, and the BEs are particularly suitable for evaluating the hardening conditions of flowable fills as a result of the wide variation in shear wave velocities.
\end{abstract}

\section{Introduction}

Soil compaction is used for backfill and road construction. However, the soil compaction method is unsuitable for construction in urban areas because it is accompanied by vibration and noise $[1,2]$. Flowable fills, which are high flowable cementitious materials, can be effectively used for narrow trenches in which the backfill soil cannot be adequately compacted. The low compressive strength of flowable fills is adequate for reexcavation of backfilled trenches [3].

The early age strength of flowable fills is considered a major aspect of early opening to traffic. One testing method to evaluate the early age strength of cementitious materials is the penetration resistance test [4]. However, the penetration test has difficulty providing continuously monitored data because flowable fill specimens can be deformed and damaged during the tests.

Ultrasonic testing methods are widely used to evaluate the characteristics of hardened cementitious materials without any damage to specimens [5, 6]. However, monitoring the early hardening process of cementitious materials is difficult, because transducers require adequate contact pressure. When transducers are poorly coupled with cementitious materials, the test results can produce large errors. Furthermore, before hardening, the specimens can be easily deformed when they are coupled with transducers.

In this study, the characteristics of elastic waves propagating a flowable fill specimen are evaluated using embedded transducers, piezo disk elements (PDEs), and bender elements (BEs) to reduce the damage to specimens and to monitor them continuously during hardening ages.

\section{Experiment}

\subsection{Mixing materials}

Calcium sulfoaluminate (CSA) cement, sand, silt, fly ash, water, and an accelerator were used to mix a flowable fill. The ratios of the ingredients are summarized in Table 1 . The water/cement $(\mathrm{w} / \mathrm{c})$ and water/binder $(\mathrm{w} / \mathrm{b})$ ratios were 7.0 and 1.6 , respectively, where fly ash was also considered as binder materials. The CSA cement was composed of $90 \%$ ordinary Portland cement (OPC) and $10 \%$ CSA expansive admixture. The chemical components of the fly ash were mainly $\mathrm{CaO}(40.8 \%), \mathrm{SiO}_{2}(20.4 \%), \mathrm{Al}_{2} \mathrm{O}_{3}$ (11.4\%), and $\mathrm{Fe}_{2} \mathrm{O}_{3}(9.2 \%)$. Jumunjin sand was used for the mixture and had an average grain size of $0.59 \mathrm{~mm}$. Silt was used as a fine particle with an average grain size of $0.02 \mathrm{~mm}$. Sand and silt were included with proportions of $7: 3$ in the mixture. Tap water at a temperature of $20-25^{\circ} \mathrm{C}$ and an alkali-free accelerator were used.

The procedure to mix the flowable fill was as follows. First, powdery materials such as binders and aggregates were blended. The powder mixture with water was then mixed with the accelerator to obtain a fresh flowable fill.

\subsection{Specimen properties}

Properties of the flowable fill specimens prepared from the mixing ratio and procedure were evaluated for flowability, compressive strength, and bulk density. A flow test was performed to evaluate the flowability of a

\footnotetext{
Corresponding author: jongsub@korea.ac.kr
} 
fresh flowable fill using an open cylindrical mould of $150 \mathrm{~mm}$ in width and a 75-mm inner-diameter according to ASTM D6103 (2017) [7]. Cylindrical flowable fill specimens with a height of $100 \mathrm{~mm}$ and a diameter of 50 $\mathrm{mm}$ were used to evaluate unconfined compressive strength curing after 3 and 28 days. For the compressive strength tests, the loading velocities were $1 \mathrm{~mm} / \mathrm{min}$, and more than three results for each curing time were averaged to determine the strength. In addition, weights of the specimens were measured to estimate the bulk density of the flowable fill before each strength test.

Table 1. Mixing proportions of flowable fill mixture (by weight).

\begin{tabular}{ccccccccc}
\hline Fine contents [\%] & CSA cement & Sand & Silt & Fly ash & Water & Accelerator & w/c & w/b \\
\hline 50 & 0.3 & 4.9 & 2.1 & 1.0 & 2.1 & 0.018 & 7.0 & 1.6 \\
\hline
\end{tabular}

The flow consistency was measured with $220 \mathrm{~mm}$, and the unconfined compressive strengths on 3 and 28 days were 0.26 and $2.09 \mathrm{MPa}$, respectively. The bulk density was $1.75 \mathrm{t} / \mathrm{m}^{3}$.

\subsection{Wave measurement system}

A cuboid mould made from MC nylon with a $150-\mathrm{mm}$ width, 52-mm length, and 190-mm height was used to assess elastic waves propagating a flowable fill sample. BEs and PDEs in each wide wall were embedded, as shown in Fig. 1. The mixed fresh flowable fill was poured into the cuboid mould, and its characteristics were monitored using compressional waves from PDEs and shear waves from BEs with curing time.

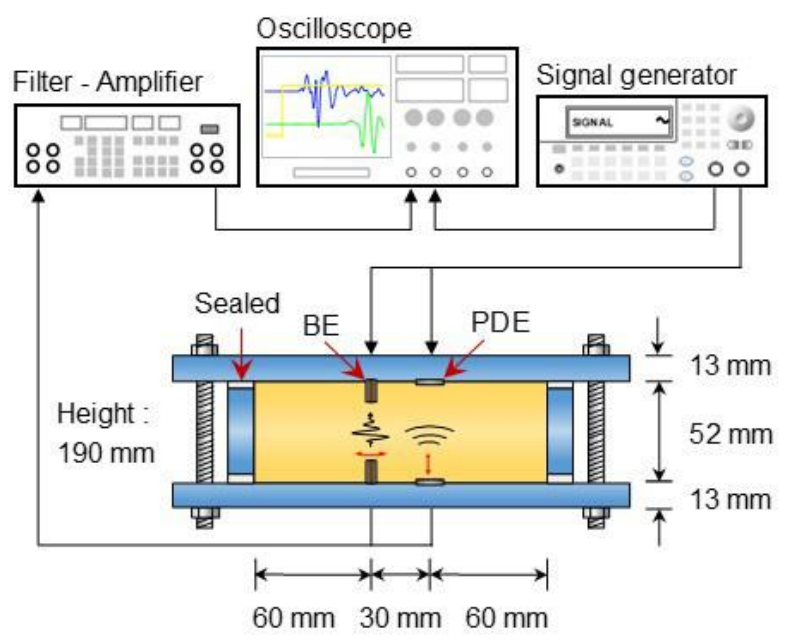

Fig. 1. Elastic wave measurement system.

The monitoring system was operated in the following manner. Input signals set up from a signal generator were transferred to either the PDE or $\mathrm{BE}$, and elastic waves were then generated by vibration from the transducers. The remaining $\mathrm{BE}$ or PDE received the elastic waves propagated into the flowable fill specimen and converted them to electrical signals. The signals were then transferred to a filter-amplifier.

The filter-amplifier removed noise from the output signals, and the output signals were finally recorded by an oscilloscope.

The input signals were established with square pulses with a frequency of $20 \mathrm{~Hz}$. Frequencies higher than 1 $\mathrm{MHz}$ from PDEs and $100 \mathrm{kHz}$ from BEs were excluded from the filter-amplifier. The elastic waves from the transducers were measured for $72 \mathrm{hrs}$.

\section{Results}

\subsection{Compressional waves}

Compressional waves were acquired with curing time using PDEs and are plotted in Fig. 2. The values on the $x$ axis of Fig. 2 indicate the travel times after the input signals were triggered. The compressional waves were observed over a few mili-seconds (ms). The first arrival times were reduced after each curing time passed. The first arrival times were shortened from 0.16 to $0.045 \mathrm{~ms}$.

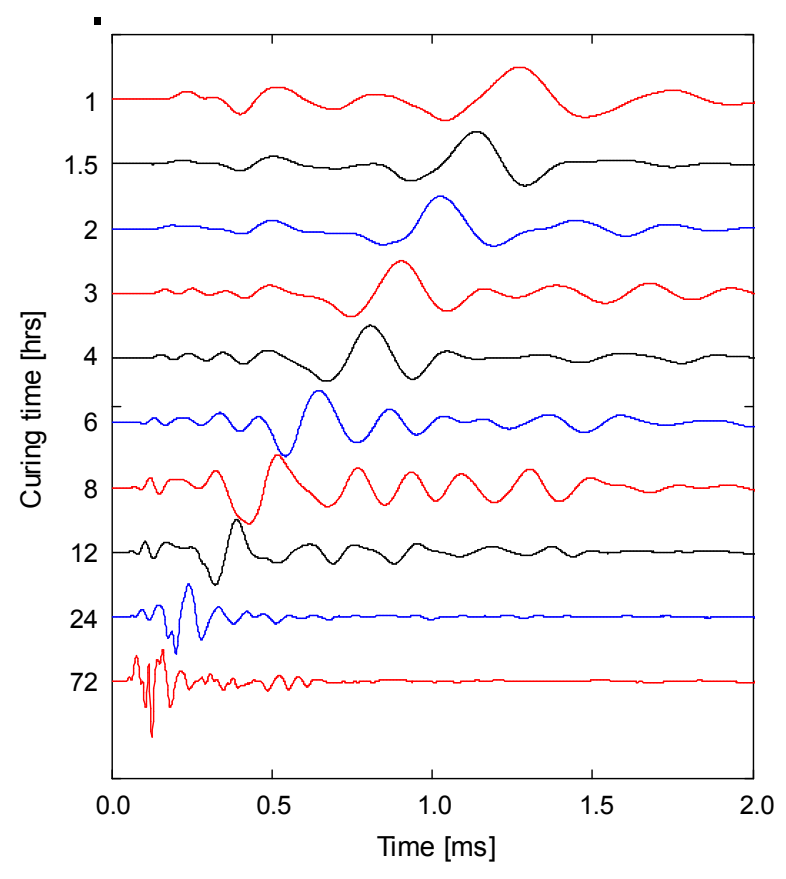

Fig. 2. Compressional wave signals with curing time.

\subsection{Shear waves}

Shear wave signals from BEs with curing time were also acquired and are represented in Fig. 3. As the curing time elapsed, the reduced travel times of the shear waves were observed. Determining accurate first arrival times on each curing time was difficult because of interference by compressional waves.

Frequency analysis was performed to reduce the influence of interfering signals and to assess the first arrival times of the shear waves. The frequency analysis is a signal processing method that uses the resonant 
frequency of measured signals. The resonant frequencies of measured signals were estimated at each curing time, as shown in Fig. 4. The resonant frequencies increased with curing time from $1.6 \mathrm{kHz}$ at $1 \mathrm{hr}$ to $44.2 \mathrm{kHz}$ at 72 hrs.

Sinusoidal pulses as input signals with the same frequencies as the resonant frequencies at each curing time were set on the signal generator. From the sinusoidal pulses, shear wave signals as shown in Fig. 5 were recorded. The first arrival times of shear waves were estimated in the same manner as with the compressional waves. The first arrival times were reduced from $0.77 \mathrm{~ms}$ at $1 \mathrm{hr}$ to $0.096 \mathrm{~ms}$ at $72 \mathrm{hrs}$.

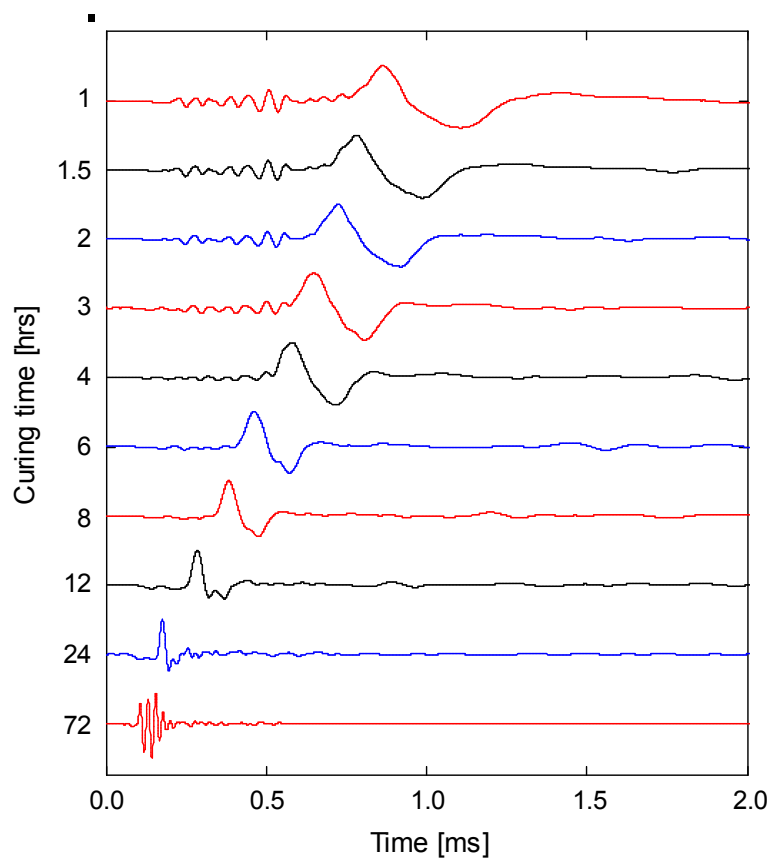

Fig. 3. Shear wave signals with curing time.

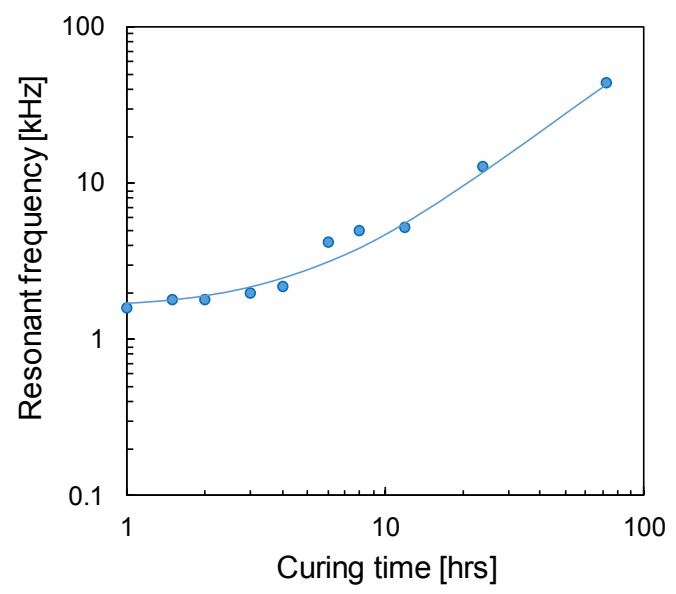

Fig. 4. Resonant frequencies of shear wave signals with curing time.

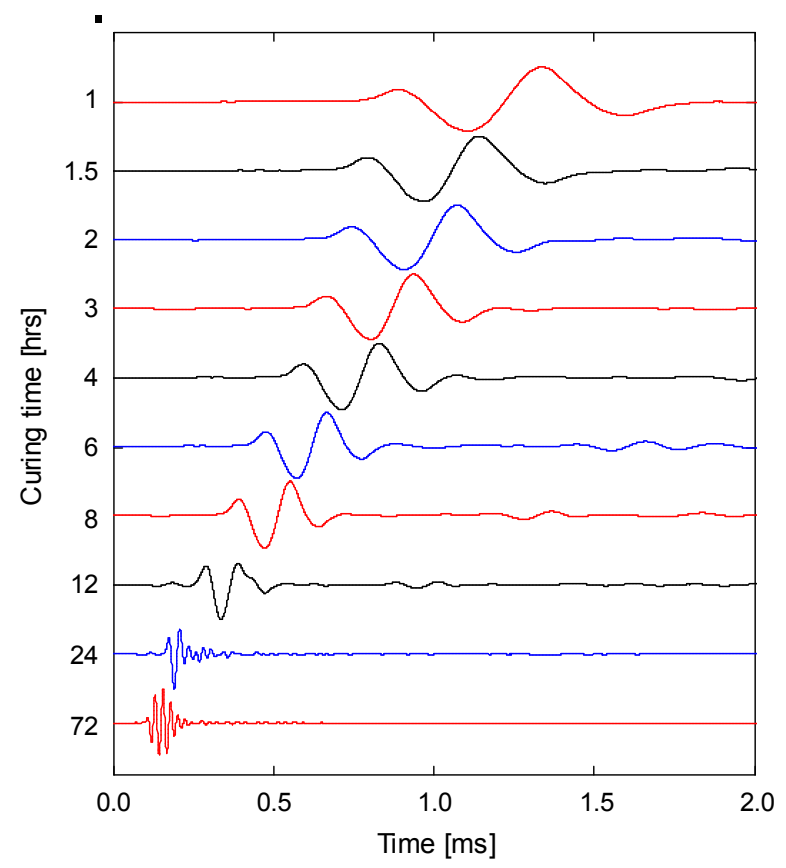

Fig. 5. Shear wave signals processed from frequency analysis with curing time.

\subsection{Wave velocities}

Wave velocities were calculated from the estimated first arrival times of elastic waves and distances between the same two transducers, as shown in Fig. 6. The compressional wave velocities were always faster than those of shear waves at every curing time.

The compressional wave velocities were calculated with $333-1156 \mathrm{~m} / \mathrm{s}$ for $72 \mathrm{hrs}$, and the shear wave velocities were estimated with $62-499 \mathrm{~m} / \mathrm{s}$. The compressional wave velocities increased sharply with curing time up to $12 \mathrm{hrs}$, but the increments decreased after 12 hrs. By contrast, the shear wave velocities increased almost linearly over $72 \mathrm{hrs}$.

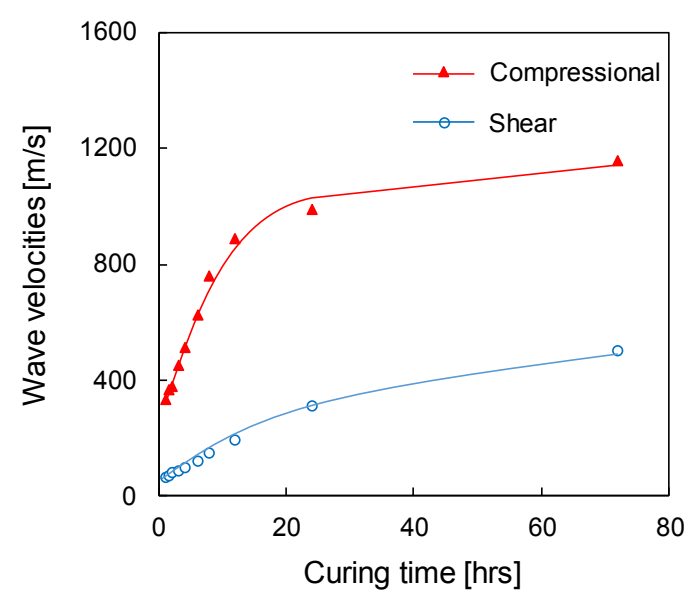

Fig. 6. Compressional and shear wave velocities with curing time. 


\section{Summary and conclusion}

In this study, embedded elastic wave transducers were used to monitor continuously the characteristics of a flowable fill mixed with CSA cement, sand, silt, fly ash, water, and an accelerator at early age for $72 \mathrm{hrs}$. Compressional and shear waves were measured from PDEs and BEs, respectively. The first arrival times of the waves were also evaluated. Regarding shear waves, the first arrival times were assessed using signals that were acquired from frequency analysis.

Both the compressional and shear wave velocities increased with curing time. The compressional wave velocities were measured as being faster than shear wave velocities on every curing time.

This research was supported by the Basic Science Research Program through the National Research Foundation of Korea (NRF) funded by the Ministry of Science, ICT \& Future Planning (NRF-2017R1A2B3008466).

\section{References}

1. National ready mixed concrete association (NRMCA), Guide specification for controlled low strength materials (CLSM), Specification Guide (1995)

2. ACI committee 229, ACI 229R-99: Report on controlled low-strengths materials (1999)

3. A. Blanco, P. Pujadas, S.H.P. Cavalaro, A. Aguado, Constr. Build. Mater. 72, 23-30 (2014)

4. ASTM C403, Standard test method for time of setting of concrete mixtures by penetration resistance, Am. Soc. Test. Mater. (2008)

5. W.J. Han, J.S. Lee, S.D. Cho, J.H. Kim, Y.H. Byun, J. Korean Geo-Environ. Soc. 16, 11 (2015)

6. B.S. Jung, J. Korea Concrete Institute. 22, 6 (2010)

7. ASTM D6103, Standard test method for flow consistency of controlled low strength material (CLSM), Am. Soc. Test. Mater. (2017) 